\title{
A cross-sectional study of growth, nutritional status and body proportions in children and adolescents at a medical center specializing in the treatment of cystic fibrosis in Poland
}

Dorota Sands ${ }^{1}$, Wioleta Umławska², Anna Zielińska

\begin{abstract}
${ }^{1}$ Cystic Fibrosis Center, Institute of Mother and Child, Warsaw, Poland 2Department of Human Biology, University of Wroclaw, Wroclaw, Poland ${ }^{3}$ Anthropology Division, Institute of Mother and Child, Warsaw, Poland
\end{abstract}

Submitted: 24 March 2012

Accepted: 17 January 2013

Arch Med Sci 2015; 11, 1: 155-163

DOI: 10.5114 /aoms.2015.49207

Copyright $@ 2015$ Termedia \& Banach

\section{Abstract}

Introduction: Malnutrition, delayed growth and delayed puberty are commonly seen in children with cystic fibrosis. The aim of this study was to evaluate growth, nutritional status and body proportions in children and adolescents suffering from cystic fibrosis.

Material and methods: The evaluation was based on 19 somatic measurements and indices calculated from these measurements. Somatic development was evaluated in relation to several factors connected to the clinical picture or the course of the disease. Anthropometric data were extracted from the medical histories of 41 boys and 48 girls diagnosed and treated at the Institute of Mother and Child in Warsaw (Poland). Mean values for somatic parameters and body build indices for the children suffering from CF were compared to those for the reference group.

Results: The results revealed that growth in these children was significantly delayed in comparison to that seen in the healthy population (Z-score = $-0.56, p<0.001)$. Nutritional status was also adversely affected $(Z$-score $=$ $-0.85, p<0.001)$. The children suffered more from a deficit in muscularity than in adiposity ( $Z$-score $=-0.75$ and $Z$-score $=-0.34, p<0.01$, respectively). This was especially true for boys. The children had infantile body proportions and defects in trunk and chest structure.

Conclusions: The factors that most affected somatic development were infection by Pseudomonas aeruginosa and the time at which the disease was diagnosed. Chronic infection by $P$. aeruginosa and type of CFTR mutation were the factors that most affected pulmonary function parameters.

Key words: cystic fibrosis, anthropometry, growth status, malnutrition, body proportions, Pseudomonas aeruginosa.

\section{Introduction}

Cystic fibrosis is one of the most common genetic metabolic disorders, and can lead to premature death. In Poland, the incidence of cystic fibrosis is 1 in 2500 live births [1]. The disease is caused by a mutation in the CFTR (cystic fibrosis transmembrane conductance regulator) gene. The product of this gene acts on cellular chloride channels and regulates trans-membrane ion transport [2]. Cystic fibrosis is associated with

\author{
Corresponding author: \\ Wioleta Umławska \\ Department \\ of Human Biology \\ University of Wroclaw \\ 35 Kuźnicza St \\ 50-138 Wroclaw, Poland \\ Phone: +48713752284 \\ Fax: +48 713752697 \\ E-mail: \\ wilota@antropo.uni.wroc.pl
}


chronic lung disease, poor digestion, malabsorption of nutrients, and malnutrition [3]. Nutritional status in patients suffering from cystic fibrosis is strongly correlated with lung function $[3,4]$.

Malnutrition, delayed growth and delayed puberty are commonly seen in children with cystic fibrosis [5-8]. The greatest delays are observed in patients who are homozygous for the F508del allele [5, 7-9]. Although significant progress has been made in the diagnosis and treatment of cystic fibrosis, physical development is slower in affected individuals than in their healthy counterparts $[6,7,10]$. On the other hand, the results of some studies indicate that intensive medical care provided in medical centers specializing in cystic fibrosis can improve nutritional status and growth rate to the point that it sometimes meets the levels for the healthy population. Such studies have been carried out, for example, at centers in Denmark and Australia [11, 12].

In addition to respiratory function, somatic development is one of the most important prognostic factors for the course of the disease and the expected lifespan of those suffering from cystic fibrosis. In one study, nutritional status was a key factor in predicting lifespan, and acted in dependently of pulmonary function in the population studied. When body weight fell below $85 \%$ of the ideal, there was a significant increase in the probability of death within the next 5 years [13]. Height is also a factor that is predictive of lifespan in those suffering from cystic fibrosis. Analysis of height in 19,000 patients treated at cystic fibrosis care centers in the United States revealed that the probability of death in individuals whose height is in the lower fifth percentile is at least three times greater than in taller individuals [14].

Delayed linear growth during the course of chronic illness causes disturbances in body proportions, especially in leg length and trunk shape. Deviation from the correct ratio of leg length to body height is a sensitive indicator of defects in somatic development that are mainly hormonal or nutritional in nature [15]. Population studies also indicate that leg length in adults is greatly affected by quality and quantity of nutrition, state of health and repetitive episodes of severe stress during childhood [16, 17].

At the same time, body proportions are relatively rarely measured when evaluating somatic development in children with chronic diseases. When measurements are performed, the results obtained are ambiguous. Leg length is significantly reduced in proportion to body height in children with connective tissue inflammation. On the other hand, sitting height is significantly reduced in children with psychogenic disturbances in appetite and in children with constitutional delayed growth and maturation [18]. Some studies indicate that children with chronic conditions such as renal insufficiency have normal body proportions even though they are shorter than normal. The reduction in leg length is proportional to the reduction in overall growth [19].

Development in individuals with cystic fibrosis has been the subject of numerous studies $[6,9$, $20,21]$. However, the authors of these studies analyzed growth rate and nutritional status primarily on the basis of the body height, body weight and body mass index (BMI). Only a few studies on limited populations have been based on more precise measurements of body proportions in children and adults suffering from cystic fibrosis [5, 8, 22] These studies revealed defects in linear proportions and severe disharmony in chest structure. In order to precisely evaluate physical development and nutritional status in children with cystic fibrosis, multiple anthropometric measurements of the patient are recommended, including measurements of circumference and skin fold thickness of different parts of the body. This permits malnutrition to be detected and effectively treated as early as possible [22].

The aim of the present study was to evaluate growth, nutritional status and body proportions in children and adolescents suffering from cystic fibrosis. The evaluation was based on 19 somatic measurements and indices calculated from these measurements. Somatic development was evaluated in relation to several factors connected to the clinical picture or the course of the disease.

\section{Material and methods}

The sample consisted of 41 boys and 48 girls diagnosed and treated at the Institute of Mother and Child in Warsaw (Poland). The children selected were between 6 and 18 years old, with a mean age of $12.3 \pm 3.5$ years. In all patients, cystic fibrosis was confirmed by positive sweat tests (chloride levels above $60 \mathrm{mEq} / \mathrm{l}$ ). All subjects were Caucasian. The study protocol was approved by the Institute of Mother and Child Ethics Committee, and written informed consent was obtained from the parents of each subject.

About 300 patients with cystic fibrosis are currently being treated at the Institute of Mother and Child. Each year, an average of 20 new cases are diagnosed. The patients included in the present study were selected at random.

Secretory deficiency of the pancreas characterized $89.9 \%$ of the children; 5 had diabetes, 4 had cirrhosis of the liver, and 3 had nonalcoholic steatohepatitis.

Anthropometric parameters were measured by trained staff in accordance with the procedures described by Martin and Knusmann [23]. 
The following data were recorded: height, weight, trunk length, leg length, shoulder width, hip width, sagittal chest depth, transverse chest width, triceps skinfold thickness, subscapular skinfold thickness, abdominal skinfold thickness, the sum of the three skinfold thicknesses, and upper arm circumference. Height was measured to an accuracy of $1 \mathrm{~mm}$. Weight was measured to an accuracy of $0.1 \mathrm{~kg}$. Widths were measured with large bow calipers to an accuracy of $1 \mathrm{~mm}$. Skinfold thicknesses were measured with an instrument produced by HOLTAIN to an accuracy of $0.2 \mathrm{~mm}$. The following ratios were also calculated: trunk length to body height, leg length to body height, hip width to shoulder width, and chest index. Upper arm muscle circumference was calculated using the following formula: arm circumference $-(\pi \times$ triceps skinfold thickness). Body mass index (BMI) was used as an indicator of relative weight, and was calculated by dividing the weight in kilograms by the square of the height in meters.

All children were treated in accordance with current CF treatment standards [24]. Alimentary therapy included diet modification with vitamin and enzyme supplements. Other therapy included physiotherapy, as well as nebulizer treatments and antibiotics for bronchopulmonary complications and chronic infection by Pseudomonas aeruginosa.

The mean age of CF diagnosis was $3.0 \pm 3.8$ years. Twenty-six patients (29.2\%) were diagnosed immediately after birth. Thirty-two patients (36.0\%) were diagnosed when they were 3 months to 3 years old. Thirty-one patients (34.8\%) were diagnosed after they were 3 years old.

Molecular DNA was analyzed an all patients in order to determine the type of CFTR gene mutation. The studies were carried out at the Medical Genetics Laboratory of the Institute of Mother and Child at the time the patients were admitted. Three groups were identified. The first group $(n=46$; $51.7 \%$ ) represented individuals with the genotype F508del/F508del. The second group ( $n=30$; $33.7 \%)$ represented individuals with the genotype F508del/Mt, and the third group ( $n=13 ; 14.6 \%)$ represented individuals with the genotype Mt/ $M t$, where $M t$ represents any mutation other than F508del.

Microbiological tests for Pseudomonas were performed on sputum specimens. If negative, they were repeated on deep swabs of the throat.

Spirometric measurements were performed during routine check-up visits at 3- to 6-month intervals. Data recorded included forced vital capacity $(F V C)$, forced expiratory volume in $1 \mathrm{~s}\left(\mathrm{FEV}_{1}\right)$ and forced expiratory flow $\left(\mathrm{FEF}_{25-75}\right)$. All spirometric parameters were measured using an MES JAEGER 100 spirometer in accordance with the procedures recommended by the Polish Phthysio-pneumological Society. All results were recorded as percentages of the predicted values, standardized for age, gender and height $[25,26]$.

To compare the size of these children with the most appropriate reference values, anthropometric parameters were expressed in terms of standard deviations of the age-specific and sex-specific reference values establish for the Polish population [27].

Differences between the sample children and the references were evaluated using Student's $t$-test for single samples. Sex differences were evaluated using Student's $t$-test or, for asymmetric distributions, the Mann-Whitney test. Asymmetry of distributions was evaluated using the Shapiro-Wilk test. The proportion of short children was also determined. Short children were defined as those who fell below two standard deviations from the reference value. This corresponds to the lower third percentile.

\section{Statistical analysis}

The effect of selected factors associated with the course of the disease on somatic development was determined using multivariate regression analysis. The dependent variables describing the status of physical development were the values of all of the somatic traits and body proportion indices. The independent values describing the course of the disease included: age at time of diagnosis, CFTR mutation type, and infection by $P$. aeruginosa. Standardized $\beta$ cofactors were used to facilitate comparison of the strength of the correlation of individual independent values with those dependent variables recorded using different units. Differences were considered significant at $p<0.05$. All analyses were carried out using the Statistica 9.0 software package.

\section{Results}

The mean z-scores of all anthropometric dimensions and the spirometric characteristics were calculated using the reference population (Tables I and II). All the somatic traits and body indices analyzed, except trunk length, hip width and abdominal skinfold thickness, differed significantly from the reference values.

This revealed that the children in the study group differed significantly in terms of body build and proportions from their healthy peers. The children studied were significantly shorter than healthy children. Ten of the children (11.2\%) had severe growth disturbances, and were therefore classified as short (Figures 1 and 2).

In comparison to healthy children, children suffering from cystic fibrosis showed distinct 
Table I. Anthropometric parameters in 89 Polish children and adolescents with cystic fibrosis, expressed in terms of standard deviations away from the means of reference values for the population of Poland

\begin{tabular}{|lccc|}
\hline Parameter & Mean Z score \pm SD & Range & Value of $p^{\text {a }}$ \\
\hline Body height & $-0.57 \pm 1.25$ & $(-4.21)-2.96$ & $<0.001$ \\
\hline Body weight & $-0.85 \pm 0.89$ & $(-2.81)-1.98$ & $<0.001$ \\
\hline BMI & $-0.77 \pm 0.79$ & $(-2.90)-2.37$ & $<0.001$ \\
\hline Leg length & $-0.79 \pm 1.23$ & $(-4.37)-2.73$ & $<0.001$ \\
\hline Ratio of leg length to body height & $-0.65 \pm 1.07$ & $(-2.91)-2.73$ & $<0.001$ \\
\hline Trunk length & $0.01 \pm 1.06$ & $(-4.07)-3.09$ & $>0.05$ \\
\hline Ratio of trunk length to body height & $0.55 \pm 0.91$ & $(-3.90)-2.18$ & $<0.001$ \\
\hline Transverse chest width & $-0.46 \pm 0.94$ & $(-2.66)-2.28$ & $<0.001$ \\
\hline Sagittal chest depth & $0.30 \pm 0.98$ & $(-1.98)-2.67$ & $<0.01$ \\
\hline Chest index & $0.77 \pm 1.28$ & $(-1.63)-4.02$ & $<0.001$ \\
\hline Shoulder width & $-0.87 \pm 1.10$ & $(-3.33)-2.74$ & $<0.001$ \\
\hline Hip width & $-0.24 \pm 1.23$ & $(-2.47)-5.99$ & $>0.05$ \\
\hline Hip to shoulder width index & $0.59 \pm 1.27$ & $(-2.66)-2.28$ & $<0.001$ \\
\hline Triceps skinfold thickness & $-0.70 \pm 0.76$ & $(-2.40)-1.94$ & $<0.001$ \\
\hline Subscapular skinfold thickness & $-0.34 \pm 1.12$ & $(-1.73)-5.13$ & $<0.01$ \\
\hline Abdominal skinfold thickness & $0.13 \pm 1.48$ & $(-1.83)-5.45$ & $>0.05$ \\
\hline Sum of three skinfold thicknesses & $-0.34 \pm 1.09$ & $(-2.11)-5.52$ & $<0.01$ \\
\hline Upper arm circumference & $-0.87 \pm 0.96$ & $(-3.12)-2.26$ & $<0.001$ \\
\hline Upper arm muscle circumference & $-0.75 \pm 1.01$ & $(-3.23)-1.81$ & $<0.001$ \\
\hline Vaues are expressed as mean Zscoses & & \\
\hline
\end{tabular}

Values are expressed as mean Z-scores (S.D.) and range. ${ }^{a}$ Student $t$-test: mean Z-score $=0$.

deviations from the norm for body proportions, linear proportions and chest structure. The ratio of leg length to body height was lower than in the reference group. On the other hand, the ratio of trunk length to body height was higher. The children with cystic fibrosis had short legs and long trunks in relation to their height. They therefore tended to retain infantile body proportions (Table I).

Sagittal chest depth was high in relation to transverse chest width. Mean values for the chest index were thus higher than in healthy children.

Mean values for the hip width to shoulder width index were also elevated. This was because shoulder width was lower than in healthy children, while hip width was about the same.

The children studied were, on average, underweight and had significantly reduced BMIs. Fifteen children (17\%) had BMIs in the lower third percentile, which is indicative of severe malnutrition. On the other hand, one of the girls studied was clinically obese (Figures 3 and 4).

Decreased body mass was primarily the result of a deficit in muscle and subcutaneous adipose tissue, localized especially in the limbs and upper part of the trunk. The children studied suffered more from a deficit in muscularity than in adipos- ity. This was especially true for boys. This is confirmed by the mean standard values for skinfold measurements, arm circumference and arm muscle circumference (Tables I, II).

Status of infection by $P$. aeruginosa was classified in accordance with the diagnostic criterion proposed by Lee et al. [28]. In the 12 months prior to the study, 31 (38.2\%) children showed no signs of infection. Sixteen (18.0\%) children were positive for intermittent infection. Thirty-nine (43.8\%) children were positive for chronic infection.

Also estimated were the independent effect of selected factors connected to the clinical picture and the course of the disease on the status of physical development and the results of pulmonary function tests. The factors studied were age at time of diagnosis, type of CFTR mutation and infection by $P$. aeruginosa. Results are presented in Table III.

The primary factor affecting the somatic development was infection by $P$. aeruginosa. Negative $\beta$ values indicate that the frequency of infection was consistently correlated with reduced values for the following parameters: body height, body weight, BMI, three skinfold thicknesses, sum of three skinfold thicknesses, hip width, arm circumference and arm muscle circumference. 
Table II. Anthropometry and spirometric characteristic of examined boys and girls with cystic fibrosis standardized for age and gender against the Polish reference group

\begin{tabular}{|c|c|c|c|}
\hline Parameter & Boys $(n=41)$ & Girls $(n=48)$ & Value of $p$ \\
\hline Body height & $-0.63 \pm 1.17$ & $-0.53 \pm 1.32$ & $0.699^{\mathrm{a}}$ \\
\hline Body weight & $-0.97 \pm 0.69$ & $-0.76 \pm 1.04$ & $0.278^{\mathrm{a}}$ \\
\hline BMI & $-0.88 \pm 0.59$ & $-0.67 \pm 0.82$ & $0.279^{b}$ \\
\hline Leg length & $-0.78 \pm 1.23$ & $-0.81 \pm 1.23$ & $0.899^{\mathrm{a}}$ \\
\hline Ratio of leg length to body height & $-0.47 \pm 1.10$ & $-0.81 \pm 1.06$ & $0.138^{\mathrm{a}}$ \\
\hline Trunk length & $-0.13 \pm 0.86$ & $0.12 \pm 1.20$ & $0.267^{\mathrm{a}}$ \\
\hline Ratio of trunk length to body height & $0.46 \pm 0.83$ & $0.63 \pm 0.98$ & $0.399^{a}$ \\
\hline Transverse chest width & $-0.63 \pm 0.84$ & $-0.32 \pm 1.00$ & $0.129^{a}$ \\
\hline Sagittal chest depth & $0.31 \pm 0.91$ & $0.30 \pm 1.04$ & $0.938^{\mathrm{a}}$ \\
\hline Chest index & $0.93 \pm 1.19$ & $0.64 \pm 1.35$ & $0.201^{b}$ \\
\hline Shoulder width & $-1.18 \pm 0.96$ & $-0.64 \pm 1.17$ & $0.023^{a}$ \\
\hline Hip width & $-0.42 \pm 0.88$ & $-0.09 \pm 1.46$ & $0.446^{b}$ \\
\hline Hip to shoulder width index & $0.75 \pm 0.83$ & $0.45 \pm 1.54$ & $0.218^{\mathrm{a}}$ \\
\hline Triceps skinfold thickness & $-0.67 \pm 0.72$ & $-0.72 \pm 0.80$ & $0.885^{b}$ \\
\hline Subscapular skinfold thickness & $-0.53 \pm 0.80$ & $-0.18 \pm 1.31$ & $0.043^{b}$ \\
\hline Abdominal skinfold thickness & $-0.23 \pm 1.07$ & $0.43 \pm 1.71$ & $0.034^{b}$ \\
\hline Sum of three skinfold thicknesses & $-0.55 \pm 0.77$ & $-0.16 \pm 1.27$ & $0.059^{b}$ \\
\hline Upper arm circumference & $-1.02 \pm 0.77$ & $-0.73 \pm 1.08$ & $0.154^{a}$ \\
\hline Upper arm muscle circumference & $-0.98 \pm 0.80$ & $-0.55 \pm 1.13$ & $0.041^{b}$ \\
\hline Percent of predicted FVC & $81.46 \pm 19.32$ & $80.71 \pm 19.48$ & $0.866^{a}$ \\
\hline Percent of predicted $\mathrm{FEV}_{1}$ & $79.91 \pm 23.08$ & $81.09 \pm 23.67$ & $0.634^{b}$ \\
\hline Percent of predicted $\left(\mathrm{FEF}_{25-75}\right)$ & $78.17 \pm 37.81$ & $68.54 \pm 34.15$ & $0.307^{b}$ \\
\hline
\end{tabular}

aStudent t-test; ${ }^{b}$ Mann-Whitney test.

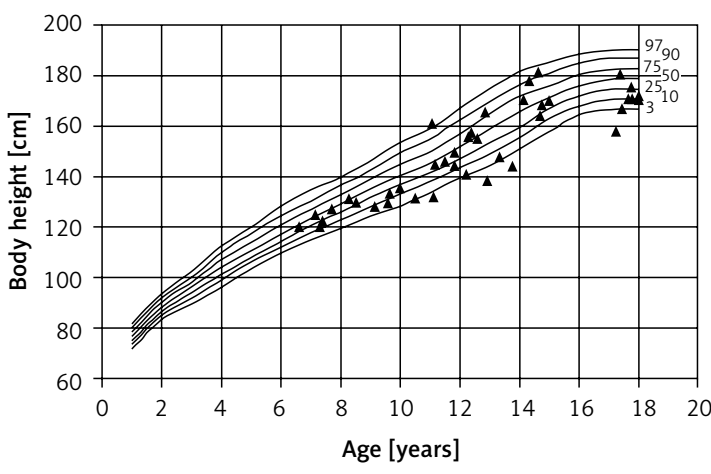

Figure 1. Percentile chart of body height of CF boys

Children with a severe course of the disease caused by chronic bacterial infection were the shortest among the children studied. They were also severely malnourished.

Positive $\beta$ values indicate that the frequency of infection was correlated with increased chest index and a highly disharmonic chest structure. Frequency of infection was correlated with increased sag-

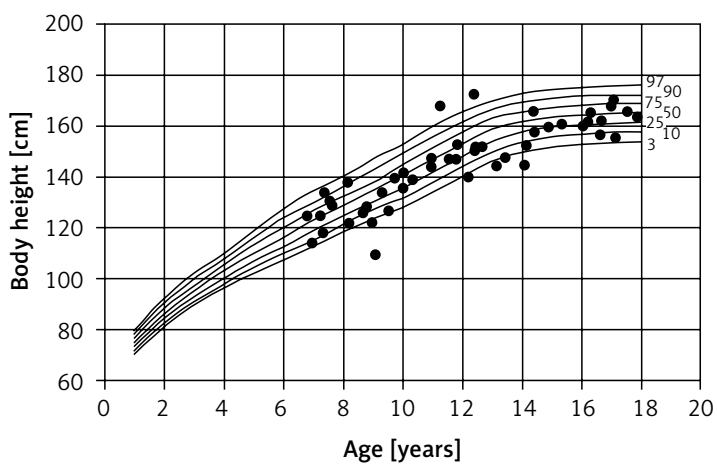

Figure 2. Percentile chart of body height of CF girls

ittal chest depth and decreased transverse chest width.

Age at time of diagnosis was a key factor affecting linear proportions and trunk structure. Generally, the earlier the disease is diagnosed, the sooner effective care and treatment can begin. In the present study, however, the children who had been diagnosed earliest had very short legs in re- 


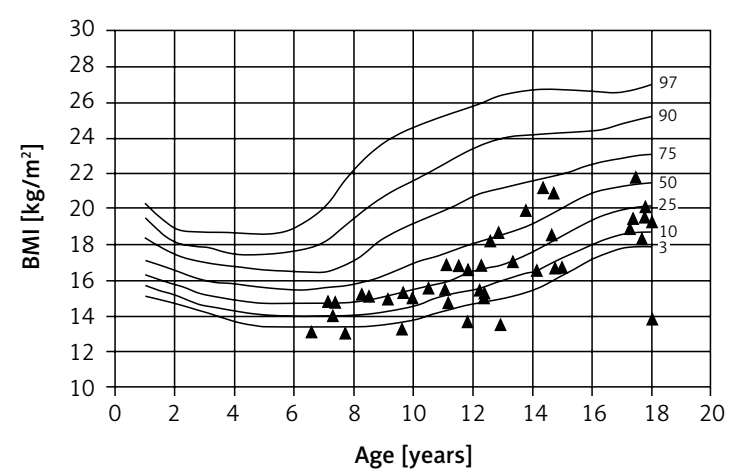

Figure 3. Percentile chart of BMI of CF boys

lation to body height and trunk length. The earlier the disease was diagnosed, the lower were the absolute values for shoulder width and hip width, and the higher were the values for sagittal chest depth. The severe disturbance of body proportions

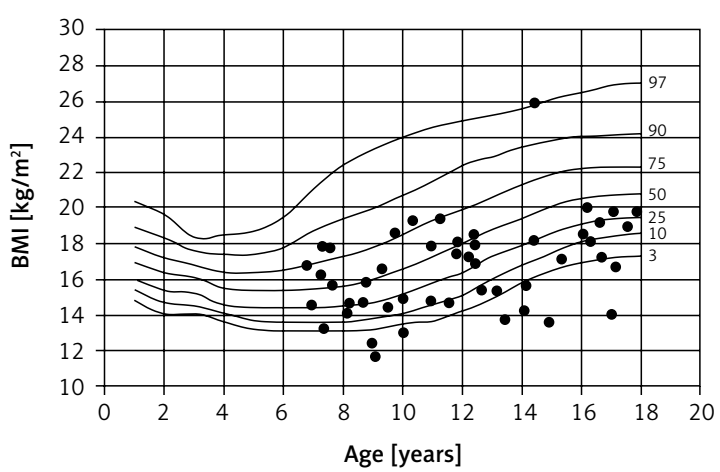

Figure 4. Percentile chart of BMI of CF girls

in the children who had been diagnosed earliest can probably be attributed to the fact that the most common mutation types severely affecting body proportions are the mutations that are detected earliest.

Table III. Results of the multiple regression analysis

\begin{tabular}{|c|c|c|c|c|c|c|}
\hline \multirow[t]{2}{*}{ Parameter } & \multicolumn{2}{|c|}{$\begin{array}{l}\text { Age at time } \\
\text { of diagnosis }\end{array}$} & \multicolumn{2}{|c|}{ Type of CFTR mutation } & \multicolumn{2}{|c|}{$\begin{array}{c}\text { Infection } \\
\text { by } P \text {. aeruginos } a^{c}\end{array}$} \\
\hline & $\beta$ & $p$ & $\beta$ & $p$ & $\beta$ & $p$ \\
\hline Body height & -0.200 & 0.0623 & -0.073 & 0.4910 & -0.218 & 0.0041 \\
\hline Body weight & -0.042 & 0.6902 & 0.016 & 0.8824 & -0.316 & 0.0032 \\
\hline BMI & 0.085 & 0.4189 & 0.020 & 0.8024 & -0.293 & 0.0060 \\
\hline Leg length & -0.443 & $<0.0001$ & -0.152 & 0.1133 & 0.057 & 0.5471 \\
\hline Ratio of leg length to body height & -0.303 & 0.0048 & -0.093 & 0.3702 & 0.013 & 0.8979 \\
\hline Trunk length & -0.421 & $<0.0001$ & -0.150 & 0.1226 & 0.076 & 0.4315 \\
\hline Ratio of trunk length to body height & 0.058 & 0.5988 & 0.025 & 0.8187 & 0.041 & 0.7114 \\
\hline Transverse chest width & 0.119 & 0.2759 & 0.058 & 0.5889 & -0.161 & 0.1346 \\
\hline Sagittal chest depth & -0.305 & 0.0037 & -0.016 & 0.8738 & 0.207 & 0.0429 \\
\hline Chest index & -0.146 & 0.1688 & 0.064 & 0.5394 & 0.254 & 0.0167 \\
\hline Shoulder width & -0.357 & 0.0006 & -0.134 & 0.1786 & 0.111 & 0.1346 \\
\hline Hip width & -0.381 & 0.0003 & -0.122 & 0.2247 & -0.003 & 0.9730 \\
\hline Hip to shoulder width index & -0.084 & 0.4440 & 0.006 & 0.9585 & -0.177 & 0.1045 \\
\hline Triceps skinfold thickness & 0.121 & 0.2466 & -0.055 & 0.5919 & -0.345 & 0.0011 \\
\hline Subscapular skinfold thickness & 0.016 & 0.8829 & -0.016 & 0.8794 & -0.215 & 0.0473 \\
\hline Abdominal skinfold thickness & -0.109 & 0.2984 & -0.219 & 0.0375 & -0.237 & 0.0244 \\
\hline Sum of three skinfold thicknesses & 0.072 & 0.5028 & -0.143 & 0.1781 & -0.280 & 0.0091 \\
\hline Upper arm circumference & -0.007 & 0.9424 & -0.077 & 0.4526 & -0.352 & 0.0009 \\
\hline Upper arm muscle circumference & 0.041 & 0.6937 & -0.074 & 0.4775 & -0.296 & 0.0057 \\
\hline Percent of predicted FVC & -0.037 & 0.7383 & -0.119 & 0.2945 & -0.279 & 0.0142 \\
\hline Percent of predicted $\mathrm{FEV}_{1}$ & -0.021 & 0.8475 & -0.239 & 0.0028 & -0.358 & 0.0012 \\
\hline Percent of predicted $\left(\mathrm{FEF}_{25-75}\right)$ & -0.059 & 0.5999 & -0.250 & 0.0302 & -0.207 & 0.0689 \\
\hline
\end{tabular}

${ }^{a}$ After 3 years old, 3 month to 3 years old, immediately after birth; ${ }^{b}$ F508del/F508del, F508del/Mt, Mt/Mt; ${ }^{c}$ Chronic infection, intermittent infection, no signs of infection. 
Infection by $P$. aeruginosa and type of CFTR mutation also affected the results of pulmonary functions tests (Table III). The lowest values for FVC were in those children with chronic infection. The lowest values for $\mathrm{FEV}_{1}$ were in children with either intermittent or chronic infection. Regardless of infection status, the lowest values for FEV 1 were in children who were homozygous for F508del. The greatest reduction in $\mathrm{FEF}_{25-75}$ was also in F508del homozygous children.

\section{Discussion}

Based on the numerous somatic traits measured and the indices calculated using them, it was possible to precisely evaluate three-dimensional body build in children with cystic fibrosis.

Mean body height was significantly lower in the children studied than in their healthy peers. The difference was even greater for mean body mass. The mean values for the anthropometric measurements revealed that the children studied suffered more from a deficit in muscularity than in adiposity. Similar results were reported in a previous study on physical development in children with cystic fibrosis [22]. The greater deficit in muscle tissue can be attributed to chronic catabolic stress and starvation. This state may be the result of a CF-related increase in muscle protein catabolism, decreased protein synthesis, increased energy expenditure, malabsorption, poor appetite and aggravated respiratory symptoms [29, 30]. In another study, examination of body structure also revealed a marked deficit in the development of fat-free mass (FFM) in affected individuals that was correlated with the severity of respiratory symptoms [31].

The children studied not only were shorter and lighter on average than healthy children but also had severe disturbances in body proportions that can be described as infantile. They were short mainly because their legs were short in relation to body height, whereas trunk length was about the same as in normal children.

The legs grow intensively during the adolescent growth spurt. Long-term studies of growth in children with cystic fibrosis have shown that the growth spurt is weaker in these children, and begins on average a year later than in healthy children. The average annual increase in height is about $1 \mathrm{~cm}$ less than in healthy children. The growth process is particularly delayed in boys [20, 21]. Other longitudinal studies confirm that the adolescent growth spurt in children with cystic fibrosis is delayed and less intense [9, 32]. Longterm observations of children with cystic fibrosis have shown that somatic development during early childhood usually proceeds normally $[9,21]$. The rapid drop in percentile values for height and weight begins at 8 years of age, and becomes more marked during puberty.

On the other hand, one study found that, in spite of the fact that children with cystic fibrosis undergo puberty later and have a less intense adolescent growth spurt, almost half of them eventually attain normal height [32]. One long-term study showed that, at age 19 , both men and women with cystic fibrosis were in the $25^{\text {th }}$ percentile for height [9]. The authors of both these studies point out that height continues to increase significantly longer in individuals with cystic fibrosis than in their healthy peers. The course of growth and maturation in individuals with cystic fibrosis is therefore consistent with the pattern of somatic development seen in children with constitutional retardation of growth and development.

In the children studied, there was severe disharmony in chest structure. Chest depth was increased in relation to chest width. The chest index was higher in affected children than in their healthy peers. This characteristic chest structure is observed in both children and adults with cystic fibrosis, and remains present even after intensive treatment and rehabilitation [4, 5, 7]. This chest structure is also seen in individuals with chronic respiratory disorders such as asthma or chronic obstructive pulmonary disease. Among the most common defects in chest structure are barrel chest, pigeon chest and Harrison's grooves [33]. These defects are caused by long-term exertion by the respiratory muscles, severe bronchial obstruction, coughing attacks and recurrent shortness of breath [34].

The children studied also had narrow shoulders in relation to hip width. It can be assumed that changes in the proportions of the chest cause the shoulders to slump forward, therefore making them appear narrower. Increased activity of the scalene, pectoralis major, sternocleidomastoid and latissimus dorsi muscles raise the shoulder joint or protract the shoulders and head forward [34].

In the present study, the most severe chest defects were seen in children with chronic infection by $P$. aeruginosa. This bacterium is the most common respiratory tract pathogen seen in individuals with cystic fibrosis. It is found in $20 \%$ to $40 \%$ of young children and over $80 \%$ of adults with cystic fibrosis $[35,36]$. Numerous studies have examined the effect of infection by $P$. aeruginosa on the clinical picture of individuals with cystic fibrosis. These studies revealed a rapid drop in $\mathrm{FEV}_{1}$ and a worsened state of the respiratory system as revealed by radiography in both children and adults [37-45]. Other findings include more frequent hospitalization, increased risk of death, and shorter survival time in infected individuals than in non-infected individuals with cystic fibrosis $[35,36]$. The FEV ${ }_{1}$ is 
on average $10 \%$ lower in uninfected patients than in affected patients. The drop in $\mathrm{FEV}_{1}$ is a gradual process rather than a sudden occurrence, and takes place even if optimal medical care is provided [39, 41, 43]. There is also a direct relation between infection by $P$. aeruginosa and nutritional status. Patients with chronic infection have a poor nutritional status based on body weight percentile or weight-for-height values [37, 42].

In the present study, infection by $P$. aeruginosa directly affected somatic development in children and adolescents independent of any other factors associated with the course of the disease. Patients with chronic infection were severely underweight because of a deficit of muscle tissue and subcutaneous adipose tissue. Their growth was also significantly delayed. Chronic infection by $P$. aeruginosa aggravated the disharmony in chest structure in the patients studied.

The present study is one of the most comprehensive studies on body structure and proportions in individuals with cystic fibrosis to date. This makes it difficult to compare the results to those of previous studies. One of the studies with interesting results is the aforementioned longitudinal study by Haeusler et al. [9]. In that study, 139 individuals with cystic fibrosis were followed from birth to age 19. In addition to regular monitoring of somatic growth, the effect of selected factors on the growth process was also observed. Infection by $P$. aeruginosa had no adverse affect on growth rate. The authors point out, however, that chronic infection by $P$. aeruginosa was most frequently observed during late adolescence, when the linear growth process was essentially completed. On the other hand, they did report that infection by $P$. aeruginosa had a marked adverse affect on nutritional status. In the present study, the average age of the subjects in each of the three infection categories was about the same, and was 11.4 years for uninfected subjects, 12.6 for intermittently infected subjects, and 12.9 years for chronically infected subjects. Another 10-year-long study of growth in about 200 children with cystic fibrosis revealed that the growth rate in chronically infected children was significantly reduced. The growth rate was $5.36 \mathrm{~cm} /$ year for chronically infected children, and $6.96 \mathrm{~cm} /$ year for uninfected children [43]. The authors point out that, regardless of infection by $P$. aeruginosa, most of the children studied eventually attained a height and weight within the reference range for the healthy population. In one preliminary study, children screened for cystic fibrosis were followed from birth to age 7. The study found that there were no significant differences in somatic growth parameters including height and weight between infected children and uninfected children [36].
In conclusion, the present study was carried out on a randomly selected sample of individuals with cystic fibrosis during the active stages of somatic development. The results revealed that growth in these children was significantly delayed in comparison to that seen in the healthy population. $\mathrm{Nu}$ tritional status was also adversely affected. There were severe defects in body proportions in terms of linear proportions, trunk structure and chest structure. The factors that most affected somatic development were infection by $P$. aeruginosa and the time at which the disease was diagnosed. The latter had a marked effect on linear proportions and trunk shape. Chronic infection by $P$. aerugino$s a$, on the other hand, greatly delayed the growth rate during childhood and adolescence. It also had a marked adverse affect on nutritional status by causing a deficit in subcutaneous adipose tissue and an even greater deficit in muscle tissue. Infection also cause marked disharmony in chest structure. Infection by $P$. aeruginosa and type of CFTR mutation were the factors that most affected pulmonary function parameters. Based on the results of this and previous cross-population and longitudinal studies, further in-depth clinical and auxological research is required to elucidate the details of somatic development in children with cystic fibrosis.

\section{Acknowledgments}

The authors are very grateful to the children and their parents for their patient cooperation in this study.

\section{Conflict of interest}

The authors declare no conflict of interest.

\section{References}

1. Bożkowa K, Siwińska-Gołębiowska H, Rutkowski J, Nowakowska A. Epidemiologia mukowiscydozy u dzieci w Polsce [Polish]. Ped Pol 1971; 46: 677-84.

2. Barboza AIM, Brandão de Mattos CC, Ferreira AIC, et al. Hypertonic saline solutions do not influence the solubility of sputum from secretor and non-secretor cystic fibrosis patients. Arch Med Sci 2011; 7: 326-21.

3. Sinaasappel M, Stern M, Littlewood J, et al. Nutrition in patients with cystic fibrosis: a European Consensus. J Cyst Fibrosis 2002; 1: 51-5.

4. Umławska W, Rams M. Physical development and pulmonary function in children and adolescents treated at two cystic fibrosis treatment centers in Poland. Arch Med Sci 2009; 5: 586-88.

5. Kosińska M, Szwed A, Cieślik J, et al. Assessment of the biological condition and nutritional status of adult patients with cystic fibrosis. Anthropol Rev 2005; 68: 53-64.

6. Laursen EM, Koch C, Petersen JH, Muller J. Secular changes in anthropometric data in cystic fibrosis patients. Acta Paediatr 1999; 88: 169-74.

7. Umławska W, Sands D, Zielińska A. Age of menarche in girls with cystic fibrosis. Folia Histochem Cytobiol 2010; 48: 171-6. 
8. Umławska W, Susanne C. Growth and nutritional status in children and adolescents with cystic fibrosis. Ann Hum Biol 2008; 35: 145-53.

9. Haeusler G, Frisch H, Waldhor T, Gotz M. Perspectives of longitudinal growth in cystic fibrosis from birth to adult age. Eur J Pediatr 1994; 153: 158-63.

10. Morison S, Dodge JA, Cole TJ, et al. Height and weight in cystic fibrosis: a cross sectional study. Arch Dis Child 1997; 77: 497-500.

11. Collins CL, MacDonald-Wicks L, Rowe S, et al. Normal growth in cystic fibrosis associated with a specialized centre. Arch Dis Child 1999; 81: 241-6.

12. Nir M, Lanng S, Johansen H, Koch C. Long term surviv al and nutritional data in patients with cystic fibrosis treated in a Danish centre. Thorax 1996; 51: 1023-7.

13. Sharma R, Florea V, Bolger A, et al. Wasting as an independent predictor of mortality in patients with cystic fibrosis. Thorax 2001; 56: 746-50.

14. Beker LT, Russek-Cohen E, Fink RJ. Stature as a prognos tic factor in cystic fibrosis survival. J Am Dietetic Assoc 2001; 101: 438-42.

15. Bogin B, Smith P, Orden AB, et al. Rapid change in height and body proportions of Maya American children. Am J Hum Biol 2002; 14: 753-61.

16. Gunnel DJ, Smith GD, Frankel SJ, et al. Socio-economic and dietary influences on leg length in childhood: a reanalysis of the Carnegie (Boyd Orr) survey of diet and health in prewar Britain (1337-39). Paediatr Perinata Epidemiol 1998; 12 (Suppl. 1): 96-113.

17. Leah LI, Dangour AD, Power C. Early life influences an adult leg and trunk length in the 1958 British birth cohort. Am J Hum Biol 2007; 18: 836-43.

18. Gohlke BC, Frazer FL, Stanhope R. Body mass index and segmental body proportion in children with different subtypes of psychosocial short stature. Eur J Pediatr 2002; 161: 250-54.

19. de Graaff LCG, Mulder PGH, Hokken-Koelega AC. Body proportions before and during growth hormone therapy in children with chronic renal failure. Pediatr Nephrol 2003; 18: 679-84

20. Byard PJ. Relationship between clinical parameters and linear growth in children with cystic fibrosis. Am J Hum Biol 1989; 1: 719-25.

21. Byard PJ. The adolescent growth spurt in children with cystic fibrosis. Ann Hum Biol 1994; 21: 229-40.

22. Stapleton D, Kerr D, Gurrin L, et al. Height and weight fail to detect early signs of malnutrition in children with cystic fibrosis. J Pediatr Gastr Nutr 2001; 33: 319-25.

23. Martin R, Knusmann R. Anthropologie. Handbuch der vergleichenden. Biologie des Menschen. Vol. 1. Gustav Fischer; Stuttgart, New York 1988.

24. Kerem E, Conway S, Elborn S, Heijerman H. Standards of care for patients with cystic fibrosis: a European Consensus. J Cyst Fibrosis 2005; 4: 7-26.

25. Tomalak W, Radliński J, Pogorzelski A, Doniec Z. Reference values for forced inspiratory flows in children aged 7-15 years. Pediatr Pulmonol 2004; 38: 1-4.

26. Willim G, Kurzawa R, Mazurek H, et al. Predicted values of respiratory indicators in children and adolescents [Polish]. IGiChP Oddział w Rabce, 1-62, 1998.

27. Palczewska I, Niedźwiedzka Z. Somatic development indices in children and youth of Warsaw [Polish]. Med Wieku Rozwoj 2001; 5: 19-55.

28. Lee T, Brownlee K, Conway S, et al. Evaluation of a new definition for chronic Pseudomonas aeruginosa infection in cystic fibrosis patients. J Cyst Fibrosis 2003; 2: 29-34.
29. Holt TL, Ward LC, Francis PJ, et al. Whole body protein turnover in malnourished cystic fibrosis patients and its relationship to pulmonary disease. Am J Clin Nutr 1985; 41: 1061-6.

30. Miller M, Ward LC, Francis PJ, et al. Altered body composition and muscle protein degradation in nutritionally growth-retarded children with cystic fibrosis. Am J Clin Nutr 1982; 36: 492-9.

31. Ionescu AA, Nixon LS, Evans WD, et al. Bone density, body composition, and inflammatory in patients with cystic fibrosis. Am J Resp Crit Care Med 2000; 162: 789-94.

32. Aswani N, Taylor CJ, McGaw J, et al. Pubertal growth spurt in cystic fibrosis: a retrospective review. Acta Paediatr 2003; 92: 1029-32.

33. McNicol KN, Williams HE, Gillam GL. Chest deformity, residual airways obstruction and hyperinflation, and growth in children with asthma. I: Prevalence findings from an epidemiological study. Arch Dis Child 1970; 40: 783-8.

34. Lopes EA, Fanelli-Galvani A, Prisco CCV, et al. Assessment of muscle shortening and static posture in children with persistent asthma. Eur J Pediatr 2007; 166: 715-21.

35. Fitzsimmons SC. The changing epidemiology of cystic fibrosis. J Pediatr 1993; 122: 1-9.

36. Nixon GM, Armstrong DS, Corzino R, et al. Clinical outcome after early Pseudomonas aeruginosa infection in cystic fibrosis. J Pediatr 2001; 158: 699-704.

37. Emerson J, Rosenfeld M, McNamra S, et al. Pseudomonas aeruginosa and other predictors of mortality and morbidity in young children with cystic fibrosis. Pediatr Pulmonol 2002; 34: 91-100.

38. Henry RL, Mellis CM, Petrovic L. Mucoid Pseudomonas aeruginosa is a marker of poor survival in cystic fibrosis. Pediatr Pulmonol 1992; 12: 158-61.

39. Kerem E, Corey M, Gold R, Levison H. Pulmonary function and clinical course in patients with cystic fibrosis after pulmonary colonization with Pseudomonas aeruginosa. J Pediatr 1990; 116: 714-9.

40. Konstan MW, Butler SM, Wohl ME, et al. Growth and nutritional indexes in early life predict pulmonary function in cystic fibrosis. J Pediatr 2003; 142: 624-30.

41. Kosorok MR, Zeng L, West S, et al. Acceleration of lung disease in children with cystic fibrosis after Pseudomonas aeruginosa acquisition. Pediatr Pulmonol 2001; 32: 277-87.

42. Lebecque P, Leal T, Zylberger K, et al. Towards zero prevalence of chronic Pseudomonas aeruginosa infection in children with cystic fibrosis. J Cyst Fibrosis 2006; 5: 237-44.

43. Pamukcu A, Bush A, Buchdahl R. Effects of Pseudomonas aeruginosa colonization on lung function and anthropometric variables in children with cystic fibrosis. Pediatr Pulmonol 1995; 19: 10-5.

44. Que C, Cullinan P, Geddes D. Improving rate of decline of FEV1 in young adults with cystic fibrosis. Thorax 2006; 61: 155-7.

45. Sagel SD, Gibson RL, Emerson J, et al. Impact of Pseudomonas and Staphylococcus infection on inflammation and clinical status in young children with cystic fibrosis. J Pediatr 2009; 154: 183-8. 